SCARA-1.02-10, (77)

\title{
The Relation between Burning Time and Burning Energy of HTPB - Based Composite Propellant
}

\author{
Ameer Awad Ebrahim Osman* \\ ${ }^{*}$ Defense Industries System, Sabighat Industrial Complex, Sudan \\ Email: ameerlin@ hotmail.com
}

\begin{abstract}
This paper represented a result of several visions of chemical phenomenon and several extractions and extrapolations of experimental works which included a relationship between energy related to a chemical process and the relevant time which is required to achieve this process, but it must be taken into account that those mentioned experimental works hadnt aimed substantially to study and state this relationship neither implicitly nor explicitly, but the results of those works have been exploited for another field after being compared with the relevant thermodynamic calculations. The selected case study for this paper was the relation between the burning time of Hydroxyl terminated poly butadiene propellant ( HTPB) and the caloric value of this material. The results reflected some relationship between the burning time and the change of the system energy during the burning process.
\end{abstract}

Key words-Burning Time ,Burning Energy, HTPB propellant.

\section{INTRODUCTION}

\section{A. Heat of Chemical Reaction and Time of Reaction}

Heat of chemical reaction represents the increase or decrease of the system energy due to a chemical reaction, the increase occurs if the reaction is exothermic while the decrease occurs in the case of endothermic reaction. But before studying the relationship between the heat of reaction and the time of reaction we must distinguish the term of the time required to accomplishment of chemical reaction in macroscopic point of view from the term of the time of chemical reaction in macroscopic view. For the chemical reaction:

$$
a A+b B \rightarrow c C
$$

The time of reaction in microscopic view is the period of time during which a molecules of reactant $\mathrm{A}$ collide $\mathrm{b}$ molecules of reactant $\mathrm{B}$ and accordingly the bonds in $\mathrm{A}$ and B destroy, then formed fragments-atoms or radicalsrearrange through new bonds forming $\mathrm{c}$ molecules of product $\mathrm{C}$, considering all these events from the moment of collision between the a molecules of reactant $\mathrm{A}$ and the $\mathrm{b}$ molecules of reactant $\mathrm{B}$. In this prospective the time of chemical reaction is definitely small-several or less microseconds. But the time of chemical reaction in macroscopic view is the time required to achieve $\mathrm{X}$ conversion for molar flow rate FA0 of reactant $\mathrm{A}$ in a continuous stirred tank reactor-CSTR-or other like reactors, or the time required to achieve $\mathrm{X}$ conversion for initial amount NA0 of reactant $A$ in a batch reactor under specific conditions of temperature, pressure, initial concentrations of reactants and catalyst kind and amount in case of catalytic reactions. This time is considered in this paper. For batch reactor and constant volume system this considered time is calculated as follows [2]:

$$
t=\left(\frac{N A_{0}}{V}\right) \int_{0}^{X A} \frac{d X A}{-r A}
$$

Where:

$A$ :the reactant which is considered the basis of calculations. $N A 0$ : initial number of moles of reactant $\mathrm{A}$ in the rector. $V$ :volume of reactor- mixture of reaction-. $X_{A}$ : conversion achieved after $\mathrm{t}$ period of time. It is calculated as follows:

$$
X_{A}=\left(N_{A 0}-N_{A}\right) / N_{A 0}
$$

Where $N_{A}$ is unreacted amount of reactant A. -rA: rate of reaction, the minus sign here means rate of consumption or rate of disappearance because $\mathrm{A}$ is reactant substance i.e. disappears during the course of reaction. The rate of reaction has several formulas change according to the type of reaction and its conditions, one common formula is:

$$
-r A=k \prod C_{i}^{\propto_{i}}
$$

Where:

$k$ : rate constant which is function of temperature of reaction. $C_{i}$ : concentration of reactant i. $\propto_{i}$ : order of reaction according to reactant $\mathrm{i}$.

For studying the relation between the chemical energy-heat of reaction- and the time of reaction-required to achieve the reaction under specific conditions, we study two chemical reactions, one in gas phase and other in liquid phase.

1) The reaction of decomposition of acetaldehyde $\mathrm{CH}_{3} \mathrm{CHO}$ to form carbon monoxide $\mathrm{CO}$ and hydrogen methane $\mathrm{CH}_{4}$ : In 1926, Hinshelwood and Hutchison carried out a reaction of decomposition of $\mathrm{CH} 3 \mathrm{CHO}$ to $\mathrm{CH} 4$ and $\mathrm{CO}$ in gaseous phase according to the following chemical equation:

$$
\mathrm{CH}_{3} \mathrm{CHO} \rightarrow \mathrm{CH}_{4}+\mathrm{CO}
$$

And this have been carried out in a batch reactor under isothermal conditions of $518 \mathrm{~K}$ and $48.8 \mathrm{kPa}$, and effective mixing to obtain homogeneous mixture. Thus, they obtained the 
following results of change of partial pressure of acetaldehyde with time [5]:

TABLE I

PRESSURE AS A FUNCTION OF TIME OF THE REACTION OF DECOMPOSITION OF $\mathrm{CH} 3 \mathrm{CHO}$ TO $\mathrm{CH}_{4}$ AND $\mathrm{CO}$.

\begin{tabular}{lllllll}
\hline Time/[sec] & 42 & 105 & 242 & 480 & 840 & 1440 \\
Pressue/[KPa] & 43.9 & 38.6 & 30.6 & 22.6 & 15.9 & 10.5 \\
\hline
\end{tabular}

For calculating the heat of reaction corresponding to each time it must firstly calculating the relevant conversion from the following relation:

$$
X_{A}=\left(P_{A 0}-P_{A}\right) / P_{A 0}
$$

Where:

$P_{A 0}$ : initial partial pressure.

$P_{A}$ : partial pressure at time t.

Then calculating the heat of reaction per mole considering total conversion from the following thermodynamic reactions (3):

$$
\triangle H=\triangle H(298)+C p_{m h}(T 298)
$$

Where:

$\triangle H$ : heat of reaction at temperature $\mathrm{T}$.

$\triangle H(298)$ : heat of reaction at $298 \mathrm{~K}$.

$$
\triangle H(298)=\sum H(p, 298)+\sum(r, 298)
$$

Where:

$\sum H(p, 298)$ : sum of enthalpies of formation of reactants at $298 \mathrm{~K}$.

$\sum(r, 298)$ : sum of enthalpies of formation of products at $298 \mathrm{~K}$.

$C p_{m h}$ : mean heat capacity for calculating enthalpy of reaction.

$C p_{m h} / R=A+B T a m+(C / 3)(4 T a m 2 T 1 T 2)+(D / T 1 T 2)$

R: ideal gas constant.

T1, T2: temperatures at which the heat capacity is calculated which equal here $298 \mathrm{~K}$ and $518 \mathrm{~K}$.

Tam: arithmetic mean of temperatures.

$$
\operatorname{Tam}=(T 1+T 2) / 2
$$

A, B, C, D: constants related to the components of the reaction's system i.e. reactants and products, which are for the considered reaction as follows [3]:

TABLE II

CONSTANTS OF HEAT OF REACTION OF DECOMPOSITION OF $\mathrm{CH}_{3} \mathrm{CHO}$ TO $\mathrm{CH}_{4}$ AND $\mathrm{CO}$.

\begin{tabular}{llllll}
\hline Species & $A$ & $B /{ }^{*} 10^{3}$ & $C /{ }^{*} 10^{6}$ & $D /{ }^{*} 10^{-5}$ & $\mathrm{H}(298)$ \\
\hline $\mathrm{CH}_{3} \mathrm{CHO}$ & 1.693 & 17.978 & -6.16 & & -166190 \\
$\mathrm{CO}$ & 3.379 & 0.577 & - & -0.031 & -110525 \\
$\mathrm{CH}_{4}$ & 1.702 & 9.081 & -2.16 & & -74520 \\
\hline
\end{tabular}

Substituting in above thermodynamic relations we obtain the following result:

$$
\triangle H=-18774.44 \mathrm{~J} / \mathrm{mol}
$$

Then we multiply $\triangle H, N_{A 0}$ and $X_{A}$ each by other to obtain the heat of reaction of $N_{A 0}$ moles and $X_{A}$ conversion where:

$$
N_{A 0}=V P_{A 0} /(R T) .
$$

$\mathrm{R}$ : the perfect gas constant $-8.314 \mathrm{j} / \mathrm{mol} \mathrm{K}$-. Substituting in above relation per volume unit $-1 \mathrm{~m}^{3}$ we obtain:

$N_{A 0}=7.36 \mathrm{~mol}$

And at each conversion related to each time we obtain the following results:

TABLE III

RESULTS OF THE RELATION BETWEEN TIME AND HEAT OF REACTION OF DECOMPOSITION OF $\mathrm{CH}_{3} \mathrm{CHO}$.

\begin{tabular}{cccc}
\hline $\mathrm{t}[\mathrm{sec}]$ & $\mathrm{XA}$ & $|\triangle H|$ & $\ln |\triangle H| / \operatorname{ln~} \mathrm{t}$ \\
\hline 42 & 0.09 & 12507.54 & 2.5 \\
105 & 0.20 & 27489.1 & 2.2 \\
242 & 0.37 & 50854.84 & 2 \\
480 & 0.53 & 72846.12 & 1.8 \\
840 & 0.67 & 92088.49 & 1.7 \\
1440 & 0.78 & 107207.49 & 1.6 \\
\hline
\end{tabular}

2) Reversible gas - phase reaction of ethanol $\mathrm{C}_{2} \mathrm{H}_{5} \mathrm{OH}$ (A) and acetic acid $\mathrm{CH}_{3} \mathrm{COOH}$ (B) resulting in formation of water $\mathrm{H}_{2} \mathrm{O}(\mathrm{C})$ and ethyl acetate $\mathrm{CH}_{3} \mathrm{COOC}_{2} \mathrm{H}_{5}$ (D) according to chemical equation::

$$
A+B \leftrightarrow C+D
$$

This reaction was carried out by Froment and Bischof in 1990 in a batch reactor of $10 \mathrm{~m}^{3}$ at $100 \mathrm{C}$ where the composition of feed is $30 \mathrm{wt} \%$ of acetic acid, $49 \mathrm{wt} \%$ of ethanol and the balance is water. The density of mixture is $1000 \mathrm{~kg} / \mathrm{m}^{3}$ (5) i.e. the system of reaction is constant volume and constant pressure the effect of pressure is negligible in liquid phase processes -. It was found that the rate of reaction rA was as follows(5):

$$
\text { - } r A=k f C A C B k r C C C D \text {. }
$$

Where:

$K r$ : rate constant of reverse reaction.

$C A, C B, C C, C D$ : Concentrations of reactants and products. equals It was found that $k f$ equals $7.93 * 10-6 \mathrm{dm}^{3} /$ (mol.sec) and the equilibrium constant- $K e$ - equals 2.93 where:

$$
K e=k f / K r \text {. }
$$

Substituting in equation (1-11) we find that $k r$ equals $2.71 * 10-6 \mathrm{dm}^{3} /(\mathrm{mol} . \mathrm{sec})$. In the proceeding section the relation between the heat of reaction and the time of reaction would be studied. (a) Calculation of heat of reaction at $373 \mathrm{~K}$ from the following relation [4]:

$$
\begin{aligned}
& \triangle H(373)=\triangle H(298)+10-3 \int \triangle C 1+ \\
& \triangle C 2 T+\triangle C 3 T 2+\triangle C 4 T 3+\triangle C 5 T 4 d T .
\end{aligned}
$$


Where: $\triangle H(298)$ : heat of reaction at $298 \mathrm{~K}$ which is calculated from relation (1-6). $\triangle C 1, \triangle C 2, \triangle C 3, \triangle C 4$ : constants of changes of heat capacities of reaction components which are calculated from the following relation:

$$
\triangle C=C(D)+C(C)-C(A)-C(B) .
$$

Where $C A, C B, C C, C D$ are heat capacity constants of reaction components which are shown accompanying with the heat if reaction at $298 \mathrm{~K}$ in the following table $(3,4)$ :

Substituting in relation (1-12) we find that: $\triangle H=-773.375$ $\mathrm{J} / \mathrm{mol}$ (b) Calculation of time of reaction at several values of conversion. Firstly, we calculate the conversion at equilibrium $\mathrm{XAe}$ which is the maximum conversion could be achieved in reversible reactions from the following relation:

$$
\begin{aligned}
K e=(C D e C C e) /(C A e C B e) . & \\
C A e & =C A 0(1 X A e) . \\
C B e & =C A 0(B X A e) . \\
\Theta B & =F B 0 / F A 0 . \\
\Theta B=(30 / 60) /(49 / 46) & =0.47 \\
\Theta C & =F C 0 / F A 0 .
\end{aligned}
$$

$\Theta C=(21 / 18) /(49 / 46)=1.095$

The figures 30,49 and 21 are the weight ratios of acetic acid, ethanol and water respectively and 60, 46 and 18 are the molecular weight of them respectively.

$$
\begin{gathered}
C C e=C A 0(\Theta c+X A e) . \\
C D e=C A 0 X A e .
\end{gathered}
$$

Substituting relations $(1-15,16,17,18,19)$ in relation Substituting relations $(1-15,16,18,19)$ in relation (1-10) considering the case before reaching the equilibrium state we obtain:

$$
\text { - } r A=k f C A 02(1 X A)(\Theta B X A) k r C A 02 X A(\Theta C+X A) .
$$

Substituting relation (2-44) in relation (2-25) we obtain:

$$
t=C A_{0} \int d X A / k f C A_{02}^{2}\left(1 X_{A}\right)\left(\Theta B X_{A}\right) k r C A_{02} X_{A}\left(\Theta C+X_{A}\right)
$$

Where $C_{A 0}$ is the initial concentration of reactant A which is calculated as follows:

$$
C_{A 0}=N_{A 0} / V .
$$

Where $V$ is the reactor volume $10 \mathrm{~m}^{3}$ and $N_{A 0}$ is the initial concentration of reactant $A$ which is calculated as follows:

$$
\begin{aligned}
N_{A 0} & =0.49 \rho V / 46=0.49^{*} 1000^{*} 10 / 46 \\
& =106.52174 \mathrm{kmol}=106521.74 \mathrm{~mol} .
\end{aligned}
$$

Substituting in relation (1-22) we obtain:

$$
C A 0=10652.174
$$

Using the following numerical formula to solve the integer (2):

$$
\int_{X_{0}}^{X_{4}} f(X) d X=\left(\frac{h}{3}\right)\left\{f\left(X_{0}\right)+4 f\left(X_{1}\right)+2 F(\square 2)+4 f\left(X_{3}\right)+f\left(X_{4}\right)\right\}
$$

Where:

$$
h=\left(X_{4} X_{0}\right) / 4
$$

And calculating the heat of reaction for several values of $N_{A 0}$ at selected conversion ratios we obtain the following results:

From above two examples we notice that there is some proportionality between the logarithm of chemical energy change of the systems energy due to chemical reaction and the logarithm of time required for this reaction to occur, and the proportion constant is the figure 2 with slight deviation from this value. This deviation is because of two reasons: (1) At the beginning of reaction, some of molecules in different sites in the space of reaction react simultaneously i.e. at the same time second or parts of second a large amount of energy liberates which increases the value of the proportion constant. (2) while the reaction progresses and approaches to the end reaches to the required conversion- the concentrations of reactants reduce whereas the concentrations of products increase and occupy large space in the reactor reaction mixture volume which reduce the chances of collision between molecules of reactants which become few comparing with the products and apart far away which leads to discontinuity of reaction i.e. the time passes while the reaction and then the change of energy due ceases which decreases the value of the proportion constant.

\section{B. Heat of Explosion and Time of Explosion.}

Heat of explosion is defined as a large amount of heat liberated due to explosive decomposition of explosive material i.e. its very fast chemical reaction generating huge amount of gases under high temperature and pressure(6).

$$
Q=|\Sigma H f \exp -\Sigma H f p| \text {. }
$$

Where:

$\Sigma H f p$ : Summation of enthalpies of formation of explosive products at the temperature of explosive temperature of the surrounding before the explosion-. $\Sigma H$ fexp : Summation of enthalpies of formation of the explosive material constituents at the temperature of the explosion. Besides, this heat could be measured practically, and we consider here the measured values available in the literature [6], [7]. While the time of explosion will be extracted from the detonation velocity, but what is the detonation velocity? Detonation velocity "v" is the rate of propagation of detonation in an explosive, if the density of the explosive at its maximum value, and if the explosive is charged into columns which are considerably wider than the critical diameter. And the critical diameter "dc" is the minimum diameter of an explosive charge at which detonation can still take place(6). The diameter used to measure the 
The 1st Scientific Conference for Aerospace Researches \& Applications Sudan (SCARA-1)

TABLE IV

RESULTS OF THE RELATION BETWEEN TIME AND HEAT OF REACTION BETWEEN ETHANOL AND ACETIC ACID.

\begin{tabular}{ccccccc}
\hline Species & $\mathrm{C} 1 / * 10^{-5}$ & $\mathrm{C} 2 / * 10^{-2}$ & $\mathrm{C} 3 / * 10^{2}$ & $\mathrm{C} 4 / * 10^{3}$ & $\mathrm{C} 5 / * 10^{6}$ & $\mathrm{Hf}(298)$ \\
\hline $\mathrm{A}$ & 1.3964 & -3.2080 & 89.8500 & 0 & 0 & -484500 \\
$\mathrm{~B}$ & 1.0264 & -1.3963 & -3.0340 & 2.0386 & -277690 \\
$\mathrm{C}$ & 2.7637 & -20.9010 & 812.500 & -14.1160 & 9.3701 & -285830 \\
$\mathrm{D}$ & 2.2623 & -6.2480 & 147.200 & 0 & 0 & -476738.7 \\
\hline
\end{tabular}

TABLE V

HEAT CAPACITY CONSTANTS OF REACTION COMPONENTS OF THE REACTION BETWEEN ETHANOL AND ACETIC ACID.

\begin{tabular}{cccc}
\hline $\mathrm{t}[\mathrm{sec}]$ & $\mathrm{XA}$ & $|\triangle H|[J]$ & $\ln |\triangle H| / \operatorname{lnt}$ \\
\hline 206.3 & 0.01 & 823812.51 & 2.6 \\
890.52 & 0.04 & 3295250.03 & 2.2 \\
2648.84 & 0.1 & 8238125.07 & 2.0 \\
4797.74 & 0.15 & 12357187.6 & 1.9 \\
8084.29 & 0.2 & 16476250.13 & 1.8 \\
58403.46 & 0.28 & 23066750.19 & 1.5 \\
\hline
\end{tabular}

detonation velocity is slightly wider than the critical diameter because the increase of diameter doesnt lead to increase the detonation velocity, e.g. if we consider a cylindrical charge of explosive of 1 meter length and $1 \mathrm{~kg}$ mass and density which is the maximum density at which and at diameter slightly wider than the critical one the detonation velocity Will be measured, we find that if the diameter increased largely than that used in measuring of velocity holding the mass and the length being constant, the volume of the charge will increase and then the density will decrease resulting in decrease of the measured detonation velocity than that mentioned in the definition above - at maximum density-. To calculate the time of explosion for several explosive materials we consider a cylindrical charge of L meter length, 10millimeter diameter which is slightly greater than the critical diameters of materials considered, and $1 \mathrm{~kg}$ mass where the related heats of explosion as mentioned in literatures are measured in Joule/kg. Then the time of explosion is calculated as follows:

$$
t=L / v .
$$

where:

$$
L=V /(\pi(d / 2) 2) .
$$

Where:

d: diameter of explosive charge. $0926441555 \mathrm{~V}$ : volume of explosive charge, where:

$$
V=m / \rho .
$$

Where $\mathrm{m}$ is the mass of charge $-1 \mathrm{~kg}$ - and $\rho$ is its density. Substituting relations (1-25) and (1-26) in relation (1-24):

$$
t=1 /(\rho v \pi(d / 2) 2) .
$$

Applying above relation using available information in the literatures about the density, the detonation velocity and the heat of explosion of considered explosive materials we obtain the following results:
Then, comparing the above results with those of the studying of the relation between heat of reaction and time of reaction -1.1- we find that here, there is some error in the value of proportion constant - difference between 2 and 2.2 this error or deviation stems from the following reasons:

1) Measuring error. The values of density, detonation velocity, and heat of explosion differentiate - but slightly - between considered literatures $(6,7)$.

2) Approximation error in calculations.

3) Error due to selection of charge diameter used $-10 \mathrm{~mm}$ , may be that the used diameters in measuring the detonation velocities less or more than this value slightly.

\section{Linear Burning Rate and Heat of Burning.}

The linear burning rate of propellant is the velocity with which a chemical reaction progresses as a result of thermal conduction and variation at right angles to the current surface of the propellant. It depends on the chemical composition, the pressure, temperature and physical state of propellant, porosity and particle size distribution of the components.etc) [6]. The gas-fume- cloud that is formed flows in the opposite direction to the direction of burning. The burning rate describes the velocity with which the volume of the burning propellant changes. It is proportional to the linear burning rate and depends on the specific shape of propellant, e.g. flakes, spheres, tubes etc. In rocket engineering burning rate means specifically the stationary progress of burning rate in the rocket chamber [6]. The propellant could be defined as an explosive material with low rate of combustion - relative to high explosive materials discussed above. May be either solid or liquid, will burn smoothly at uniform rate after ignition without depending on interaction with atmosphere [6]. Heat of burning is defined like heat of explosion by equation 2-20:

$$
Q=\left|\Sigma H_{f e x p}-H_{f p}\right| .
$$

And it represents the difference between the caloric value of the propellant material and the heat liberated due to its burning which increase the temperature of the gaseous products from the initial ambient temperature to the burning final temperature.

\section{Materials And Methods.}

\section{A. Materials of Work}

1) Equipments: Several equipments are used in this study and according to its functional series they are:

1) Preheating oven.

2) AP crusher. It is used to minimize the size of AP crystals 
TABLE VI

RESULTS OF THE RELATION BETWEEN TIME AND HEAT OF EXPLOSION OF SOME HIGH EXPLOSIVES.

\begin{tabular}{cccccccc}
\hline Explosive material & $\rho\left[K g / \mathrm{m}^{3}\right]$ & $\mathrm{v}[\mathrm{m} / \mathrm{sec}]$ & $Q[\mathrm{~J} / \mathrm{Kg}]^{*} 10^{-3}$ & $\mathrm{dc}[\mathrm{mm}]$ & $\mathrm{d}[\mathrm{mm}]$ & $t[\sec ]^{*} 10^{3}$ & $\ln Q /|\ln t|$ \\
\hline TNT & 1650 & 6940 & 4230 & 6 & 10 & 1.112 & 2.2 \\
RDX & 1850 & 8570 & 4540 & 8 & 10 & 0.8031 \\
HMX & 1900 & 9160 & 5670 & 8 & 10 & 0.7316 \\
Tetryl & 1700 & 7920 & 4630 & 6 & 10 & 0.9457 \\
AP & 1720 & 7050 & 4310 & 5 & 10 & 1.050 & 2.2 \\
\hline
\end{tabular}

3) 5liter mixer. It is used to mix the materials and prepare the slurry of the propellant.

4) Casting system. It is used to cast the slurry inside the motor.

It is worked under high pressure and law to high temperature to determine burning time and burning rate.

5) X-ray detector and monitoring system.

6) Curing oven.

7) Digital balances.

8) Strand burner.

2) Chemicals (Ingredients of Propellant).:

1) $\mathrm{AP}($ ammonium perchlorate) (oxidizer).

2) HTPB (Pre-polymer and fuel source).

3) Aluminum (Metal fuel).

4) MAPO (Tri-2-methy-1-aziridinylphosphine oxide) (Bonding agent).

5) $\mathrm{TBFe}$ (ferrocene) (Burning rate accelerator).

6) TDI(toluene diisocyanate) (Curing agent).

7) DOS(Diisoctyl sebacate) (Plasticizer).

8) $\mathrm{Bx}$ (Styrene) (Processing agent).

9) N-N diphenyl-P-phenylene diamine (Aging agent).

10) Cesium oxide (X-858) (Antioxidant ).

11) HX-103(Antioxidant.

\section{B. Methods of Work}

The following steps represent the procedure of experimental study of the relation between the burning time and the change of energy associated:

1) Preparing of propellant mixture:: Using the equipment and materials mentioned above, preparing f mixture is achieved through following steps.

1) AP Crushing This system consists mainly of crusher, hopper, separator, control valves, manometers and dust catcher. It works by compressed air. The requirements and conditions of this system to work properly are dry and purified air supplied, dry air dew point of $40{ }^{\circ} \mathrm{C}$, air of feeding under pressure of $0.2 \mathrm{MPa}$, air of crushing under pressure of 0.6 $\mathrm{MPa}$ and temperature of air inside the crusher chamber within the range of $9095{ }^{\circ} \mathrm{C}$. The crushing room consists of dew point tester to measure the dew point of the air. After the crusher be ready, the procedure is to supply the hot compressed air for one hour, load the material inside the crusher, adjust the crushing and feed valves to the required pressures 0.6 and 0.2 respectively, and then the process begins. The result fine AP is of size of $510 \mu \mathrm{m}$.
2) Preheating Of Materials Solid materials after that were heated for 8 hours or more to remove the moisture which may be occurred during crushing process, then the materials were weighted carefully.

3) Mixing Of Materials The mixing process was carried out through several steps under $b$ adding materials gradually and mixing it under different stirrer speeds to ensure homogeneity of the mixture.

4) Measuring The Viscosity Of The Slurry Slurry after mixing is put into the viscometer and the viscosity of slurry is measured to assure the processability of mixture.

5) Casting of the mixture into a block. The slurry is loaded by casting inside the block mold for strand burner and the EBM for static test.

2) Curing Process: The block and the EBM after that were put inside the curing oven for solidification under $70^{\circ} \mathrm{C}$ and for 160 hours.

3) Assuring Of Non-existence Of Defects: After curing process, the block was put into $\mathrm{X}$-ray detector to assure that there are no cracks, flaws and voids.

4) Extracting of Samples: Extracting several samples from the block eight samples at least- and using six samples to determine burning time and amount of heat liberated during the process of burning at different initial temperatures $(10,20$, 30) ${ }^{\circ} \mathrm{C}$ and different operating pressures $(4,6,8,11) \mathrm{MPa}$.

5) Strand Burner Testing: In strand burning-rate tests, a long and relatively slender section of the propellant in which wires have been embedded at specific intervals, was burned in a nitrogen atmosphere. The embedded wires have a relatively law melting point and are connected to a timing circuit. As the strand was burning in cigarette fashion, the time required to burn from one wire to an adjacent wire was measured, thus establishing a burning time.

Strands were conditioned to the desired temperature and burned in a closed chamber containing a measured amount of water to permit $\Sigma H f \exp =m s \Sigma(X i * H i / M i)$ measure the liberated heat from the burning by measuring the increment of the water temperature and multiply the temperature difference by mass of water and its heat capacity, this represents the acquired heat by water which equals the liberated heat due to burning. The pressure inside the chamber could be closely controlled by utilizing a large tank of nitrogen in series with the chamber; so, pressure rise in the chamber was held to a minimum, permitting the burning rate to be determined at a near constant pressure. 
TABLE VII

HEAT OF FORMATION OF INGREDIENTS OF PRODUCTION PROCESS OF HTPB - BASED PROPELLANT.

\begin{tabular}{cccc}
\hline Ingredient & Chemical Formula & weight fraction & {$[\mathrm{J} / \mathrm{mol}] * 10^{-} 3$} \\
\hline Al & AL 1.000 & 0.160812 & 0.000 \\
AP & H 4.000 N 1.000 O 4.000 CL 1.000 & 0.683447 & -295.965 \\
DOS & C 26.000 H 50.000 O 4.000 & 0.034910 & -1377.876 \\
TBFe & C 10.000 H 10.000 FE 1.000 & 0.015070 & 141.095 \\
HTPB & C 10.000 H 15.358 O 0.073 & 0.098501 & -51.916 \\
MAPO & C 9.000 H 18.000 N 3.000 O 1.000 & 0.001230 & -346.248 \\
TDI & C 9.000 H 6.000 N 2.000 O 2.000 & 0.006030 & -10.886 \\
\hline
\end{tabular}

TABLE VIII

RESULTS OF THE RELATION BETWEEN TIME AND HEAT OF BURNING OF HTPB-BASED PROPLLANT.

\begin{tabular}{ccccccccc}
\hline $\mathrm{mw}[\mathrm{g}]$ & $\mathrm{ms}[\mathrm{g}]$ & $\Sigma H f \exp [\mathrm{J}]$ & $\triangle T[K]$ & Pressure $[\mathrm{MPa}]$ & $\Sigma H f p[\mathrm{~J}]$ & $\mathrm{Q}[\mathrm{J}]$ & $\mathrm{T}[\mathrm{sec}]$ & $\ln \mathrm{Q} / \ln \mathrm{t}$ \\
\hline 564 & 6.425 & -11970.6 & 5 & 11 & -11787.6 & 183 & 11.674 \\
555 & 6.432 & -11983.7 & 5.1 & 11 & -11831.5 & 152.2 & 11.891 \\
562 & 6.443 & -12004.2 & 5 & 6 & -11745.8 & 258.4 & 14.371 \\
560 & 6.594 & -12285.5 & 5.1 & 6 & -11938.1 & 347.4 & 15.126 \\
562 & 6.620 & -12333.9 & 5.1 & 4 & -11980.7 & 353.2 & 16.564 \\
560 & 6.622 & -12337.7 & 5 & 4 & -11704.0 & 633.7 & 16.601 \\
\hline
\end{tabular}

\section{RESUlTS AND ANALYSIS.}

\section{A. Results.}

Carrying out several burning experiments, Recording readings from the monitor of strand burner, and using the following relations:

$$
Q=|\Sigma H f \exp -\Sigma H f p| .
$$

Where: $\Sigma H f \exp$ : Heat of formation or energy content of propellant.

$$
\Sigma H f \exp =m s \Sigma(X i * H i / M i)
$$

$m s$ mass of strand - sample of propellant.

$X_{i}$ : weight fraction of ingredient $i$.

$H_{i}$ : heat of formation of ingredient $\mathrm{i}$.

$M_{i}$ : molecular weight of ingredient $\mathrm{i}$.

$\Sigma H f p$ : heat released due to burning.

$$
\Sigma H f p=-\Sigma H w=-m w * C p w * \triangle T
$$

mw: mass of water used in the combustion chamber. Cpw: average heat capacity of water $=4.18 \mathrm{~J} / \mathrm{g} \mathrm{K} . \triangle T$ : difference between initial temperature and final temperature i.e. increase of water temperature because of burning process, and substituting data shown in Table VII [1]. Finally, the results obtained is shown in Table VIII.

\section{B. Analysis}

comparing the above results with those of the studying of the relation between heat of reaction and time of reaction 1.1- and those of the studying the relation between heat of explosion and time of explosion we find that here, there is a slight error in the value of proportion constant, this error or deviation stems from the following reasons:
1) Error of device, i.e. error due to measuring burning time and temperature increment.

2) Error of balance, i.e. error in weighting the strands propellant samples and water.

3) Error of calculations due to using average value of water heat capacity $4.18 \mathrm{~J} / \mathrm{g} \mathrm{K}$ - instead of exact value which is a function of temperature.

4) Error of approximation.

\section{Conclusion}

1) There is a direct relation between the logarithm of energy according to continuous chemical process and the logarithm of time required to achieve this process with proportion constant equals 2 . And in mathematical formula:

$$
\ln |E|=2|\ln t|
$$

2) The continuous process means the process doesn't suffer any stoppage from beginning to end, which means that any part of time-whatever its value doesn't pass during the period of the process without occurring of it. But, there are some processes suffer internal stoppagewithout intervention from surrounding because of change of their physical and chemical conditions as chemical reactions which their rates decrease as a result of decrease of reactants' concentrations because of consumption during the course of reaction. This decrease in reactions rate represents a macroscopic view of microscopic view includes parts of time-whatever their lengths in which the reaction stops in microscopic perspective i.e. the reaction between one molecule of reactant $A$ with one molecule of reactant $B$, what means a stoppage in change of energy accomplished the discontinuous process the mentioned chemical reaction while the time passes of course. 
3) For processes like this process during which the energy change stops while the time passes the constant of proportion deviates from its value -2- slightly and this could be considered an error taking into account that the stoppage of process must not because of external effect from surrounding, otherwise the deviation of the proportion constant value will be great and then it couldn't be considered just an error .

\section{RECOMMENDATIONS}

1) Carrying out more experiments to ensure this relation between energy and time.

2) Applying the law of energy and time relation 1-5 to design chemical reactors, this could be done through knowing the heat of reaction which is available in thermodynamic literatures and substituting the value of time from relation (1-5) in the following relation:

$$
V=v_{0} \rightarrow t
$$

Where $V$ is the size of reactor and $v_{0}$ is the initial volumetric flow rate of reactants and sometimes of recycled products to the reactor. This determination of the time of reaction is what we call the thermodynamic design of chemical reactors. But it may be seem that the deviation of the proportion constant from the perfect value -2 at the beginning and the end of reaction course makes the calculated time inaccurate, but there are two facts must be considered here:

a) The increase in the value of the proportion constant in the beginning of reaction would be eliminated or reduced by the decrease in its value as the reaction approaches to the end.

b) The design is approximate process. Practically, safety factor must be considered and set.

\section{REFERENCES}

[1] 1.JETSOFT COMBUS program, version 3.6, Yugoslavia, 1992.

[2] H.Scott Fogler, Elements of Chemical Reaction Engineering, 3rd Edition, Prentice Hall, Inc., New Jersey, 1999.

[3] J.M.Smith, and H.C.Van Ness, Introduction to Chemical Engineering Thermodynamics, 4th Edition, McGraw- Hill Book Company, 1987.

[4] Robert H.Perry, and Don W.Green, Perry Chemical Engineering Handbook,7th Edition, McGraw- Hill, 1997.

[5] Ronald W.Missen, Charles A.Mims, and Bradley A.Saville, Chemical Reaction Engineering and Kinetics, John Wiley \& Sons Inc., 1999.

[6] Rudolf Meyer, Josef Kohler, and Axel Hamburg, Explosives, 5th Edition, Wiley-VCH, 2002.

[7] http://stason.org, Heat of Detonation, 6 p.m. 25 Jan. 2011. 